\title{
A small change approach to prevent long-term weight gain in adults with overweight and obesity: a randomized controlled trial
}

\author{
Robert Ross PhD, Amy E. Latimer-Cheung PhD, Andrew G. Day MSc, Andrea M. Brennan PhD, James O. Hill PhD
}

Cite as: CMAJ 2022 March 7;194:E324-31. doi: 10.1503/cmaj.211041

\begin{abstract}
Background: Efforts to manage obesity through weight loss are often unsuccessful as most adults are not able to sustain the major changes in behaviour that are required to maintain weight loss long term. We sought to determine whether small changes in physical activity and diet prevent weight gain in adults with overweight and obesity.
\end{abstract}

Methods: We randomized 320 sedentary adults with overweight or obesity to monitoring alone (MA, $n=160$ ) or a small change approach (SCA, $n=160)$. In Phase I (2 yr), MA participants were asked to maintain their normal lifestyle and SCA participants were counselled to make small changes in diet and physical activity, namely a suggested increase in daily step count of 2000 steps with a decrease in energy intake of $100 \mathrm{kcal}$ per day, with group and individual support. Phase II ( 1 yr) was a passive followup period. The difference in change in body weight between groups at 24 and 36 months from baseline was the primary outcome. Additional outcomes included waist circumference and cardiorespiratory fitness.

Results: Overall, 268 participants $(83.8 \%)$ completed the 2-year intervention, and $239(74.7 \%)$ returned at the end of the follow-up period at 3 years. The difference in body weight change between the SCA and MA groups was significant at 3, 6, 12 and 15 months from baseline, but was no longer sig- nificant at 24 months (mean change 0.9 [standard error (SE) 0.5] kg v. - 0.4 [SE 0.5 ] kg; difference $-0.6,95 \%$ confidence interval $[\mathrm{Cl}]-1.9$ to 0.8 ) or at 36 months (-1.2 [SE 0.8] v. -0.7 [SE 0.8] kg; difference $-0.5,95 \% \mathrm{Cl}-2.2$ to 1.2 ). Changes in waist circumference and cardiorespiratory fitness were not significantly different between groups at 24 or 36 months (both $p>0.1$ ).

Interpretation: The SCA did not prevent weight gain compared with monitoring alone at 2 or 3 years in adults with overweight or obesity. On average, we observed prevention of weight gain in both arms of the trial. Trial registration: ClinicalTrials.gov, no. NCT02027077.

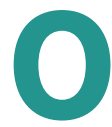

verweight and obesity contribute to chronic diseases and present a major public health challenge ${ }^{1}$ as more than $63 \%$ of adults in Canada currently live with overweight or obesity. ${ }^{2}$ Despite the urgent need to address the obesity problem, few strategies designed to reduce obesity have been broadly successful.

Results from randomized controlled trials show that most adults are not able to sustain the major changes in behaviour that are required to maintain weight loss long term. ${ }^{3,4} \mathrm{~A}$ more reasonable and achievable goal may be to focus on the prevention of weight gain. Preventing further weight gain is clinically important as even modest weight gain $(0.5-1.0 \mathrm{~kg} / \mathrm{yr})$ in adults with overweight and obesity has negative associations with adverse outcomes, such as cancer, ${ }^{5}$ all-cause and cardiovascular disease-related death ${ }^{6}$ and poor health-related quality of life. ${ }^{7}$
It has been estimated that, for $90 \%$ of the adult population, a reduction of about $100-150 \mathrm{kcal} / \mathrm{d}$ would be required to prevent positive energy balance. ${ }^{8,9}$ Two separate pilot studies have shown that a small change approach (SCA, defined as an increase in daily step count of 2000 steps or a decrease in energy intake of $100 \mathrm{kcal}$ ) prevented weight gain in a small group of adults and children with overweight over 13 weeks. ${ }^{9,10}$ More recently SCA was shown to be associated with reduced weight gain in young adults with overweight at 2 years, compared with controls. ${ }^{11}$

We sought to determine the effectiveness of the SCA to prevent weight gain in adults with overweight (defined as a body mass index [BMI] 25-29.9) and obesity (defined as a BMI of $\geq 30$ ) at 2 and 3 years. We hypothesized that the SCA would prevent weight gain in comparison with monitoring of body weight alone. 


\section{Methods}

\section{Study design, setting and participants}

Details of the trial design and methods are published. ${ }^{12}$ We conducted a 3-year, single-centre, 2-arm, open-label, longitudinal, randomized controlled trial between February 2014 and 2018. Recruitment was via media advertisement. Inclusion criteria required that participants be between 25 and 70 years old, have a BMI between 25.0 and 39.9 , be physically inactive and have a stable weight (within $2 \mathrm{~kg}$ of baseline weight) for 6 months before the beginning of the study. We excluded participants if they were current smokers, had a planned pregnancy within 3 years or reported a history of heart disease, stroke or any condition that would prevent them from engaging in exercise. All participants provided informed consent before participation.

We randomized individuals meeting the inclusion criteria to monitoring alone (MA) or to the SCA. We used a secure thirdparty, web-based platform (Randomize.net) to randomize participants. This platform generated, and had sole access to, the randomization sequence. Participants were randomized 1:1 to either the SCA or MA group, and stratified by sex using permuted blocks of random (undisclosed) size. Couples were randomized simultaneously to the same arm of the trial.

The study included 2 phases. The duration of treatment (Phase I) was 24 months, followed by a 1-year passive follow-up period (Phase II), during which all participants had contact with trial staff for body weight assessment at 30 and 36 months. Participants in both MA and SCA groups received a $\$ 100$ stipend at each of the 6-, 12-, 24- and 36-month assessments to help offset trial-related expenses.

\section{Intervention}

The intervention has been described previously. ${ }^{12}$ Briefly, we asked all MA group participants to maintain their usual lifestyle (diet and exercise) for the duration of the 2-year intervention and did not discourage them from adopting a healthy lifestyle for the purposes of preventing or losing weight. We asked participants in the SCA group to attend a combination of group and 1-on-1 sessions. The format, frequency and content of intervention sessions is described elsewhere. ${ }^{12}$ Overall, participants were offered 17 group-based sessions and 9 individual counselling sessions, representing about 20 hours of intervention contact. Initial sessions were interventionist-led, but transitioned to being directed by the participant to foster independent self-regulation of SCA behaviours. The SCA intervention comprised several behaviour techniques; the specific techniques included in the intervention are described in Appendix 1, available at www.cmaj.ca/lookup/ doi/10.1503/cmaj.211041/tab-related-content.

Participants randomized to the SCA group reviewed their progress by examining their diet and physical activity patterns, self-monitoring, setting weekly SCA goals and developing a weekly plan for ongoing maintenance of their small change goals. Participants submitted dietary and physical activity logs and their SCA plan to an interventionist on a weekly basis via electronic or paper form.

\section{Physical activity goal and monitoring}

All participants in the SCA group were asked to wear the pedometers we provided (i.e., self-monitor) and maintain their normal activity pattern during the first week after randomization. After establishing a baseline activity level (measured as steps per day), we asked each SCA participant to increase their daily physical activity by about 2000 steps per day (about 20 minutes) above the baseline value and to maintain this goal as a daily minimum for the duration of the 2-year intervention. The SCA participants selfmonitored their physical activity by recording their daily steps and submitting their records on a weekly basis, electronically or in person. We asked SCA participants to wear the pedometer at 6, 12 and 24 months for comparison with their baseline activity level.

\section{Dietary change goal and monitoring}

We asked SCA participants to reduce their usual diet by $100 \mathrm{kcal} / \mathrm{d}$. Participants recorded their usual diet using daily dietary intake records over the 2 -week period immediately after randomization. The study dietitian used diet record information, obtained using established procedures, ${ }^{12}$ to provide participants with specific, pragmatic examples of how to reduce their usual dietary intake by $100 \mathrm{kcal} / \mathrm{d}$. We asked SCA participants to keep a log each day of the strategies used to reduce caloric intake by $100 \mathrm{kcal} / \mathrm{d}$ and to submit their records on a weekly basis, electronically or in person. Participants submitted a full 7-day intake record at 12 and 24 months.

\section{Primary and secondary outcomes}

We provide a complete list of the primary, secondary and other outcomes in the trial registration in Appendix 2, available at www. cmaj.ca/lookup/doi/10.1503/cmaj.211041/tab-related-content. We obtained anthropometric measurements at baseline (before randomization) and at 3, 6, 9, 12, 15, 18, 24, 30 and 36 months from baseline. We measured body weight (primary outcome) using the same beam scale throughout the trial. Waist circumference measures were obtained at the level of the iliac crest. We also collected change in daily steps (in the SCA group) as a secondary outcome.

\section{Other outcomes}

We measured cardiorespiratory fitness $\left(\mathrm{VO}_{2}\right.$ peak) using a graded exercise test-to-exhaustion on a treadmill. ${ }^{12}$ This test was optional for participants.

\section{Adverse events}

Participants reported adverse event information (e.g., cardiovascular events, musuloskeletal injuries, hospital admissions) to the study coordinator during the trial, or the participant informed research staff directly at assessment or at any behavioral intervention meeting (for those in SCA group).

\section{Sample size}

We originally planned to enroll 354 participants to achieve at least $90 \%$ power at a 2 -sided $\alpha$ of 0.05 to detect a $2 \mathrm{~kg}$ difference between arms in our primary outcome. The sample size assumed a $5 \mathrm{~kg}$ standard deviation and up to $25 \%$ loss to follow-up. Given funding cuts, we stopped enrolment after 320 participants, which, under our initial assumptions, would achieve $87 \%$ power. 
Individuals who contacted study coordinator for information $n=838$

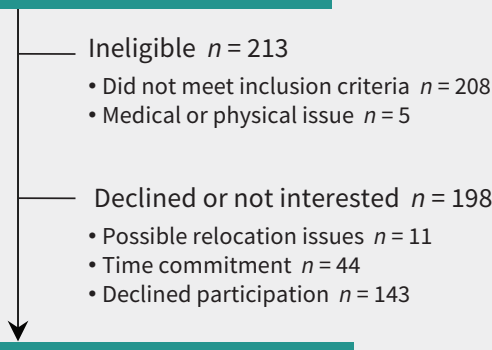

Attended orientation meeting $n=427$

Excluded $n=107$

- Did not meet inclusion criteria $n=6$

- Medical or physical issue $n=1$

- Declined participation $n=100$

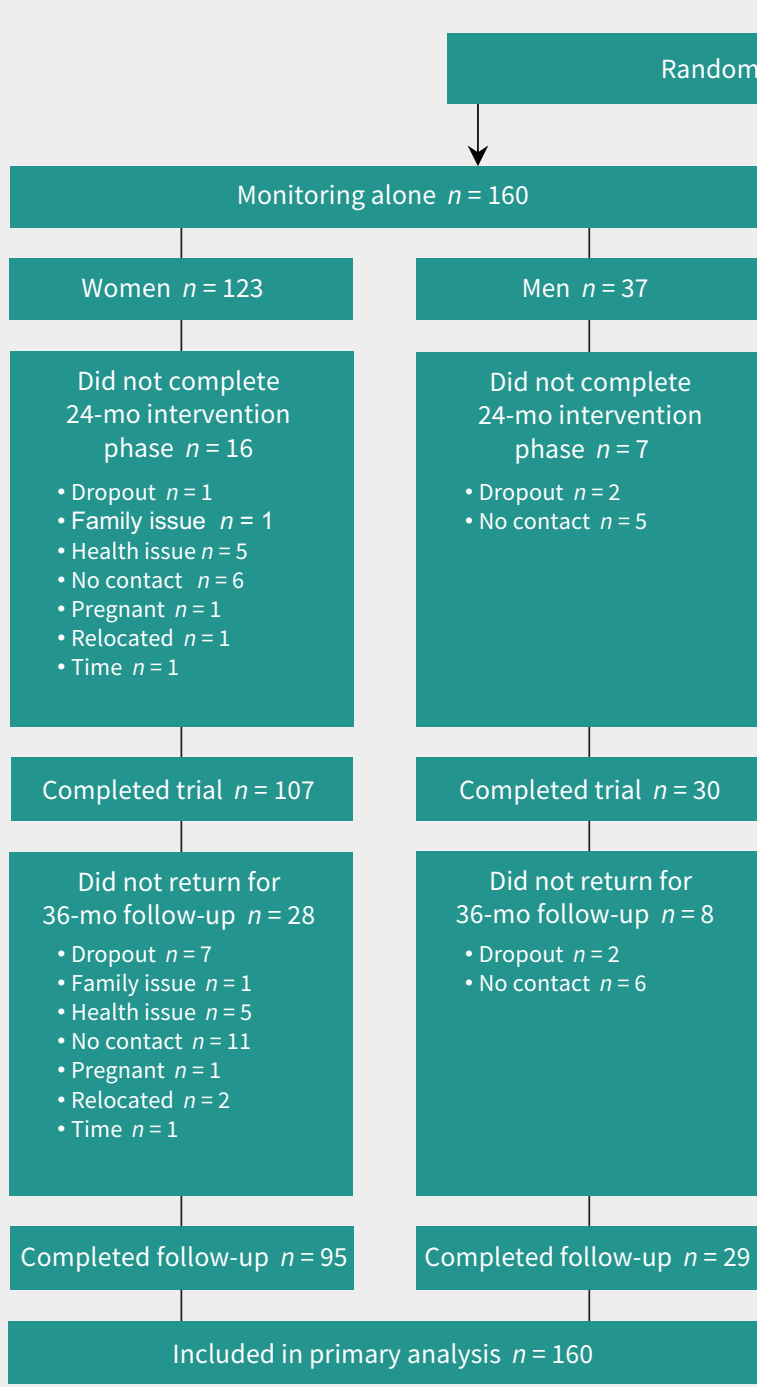

$n=320$

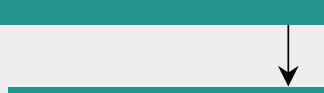

Small change approach $n=160$

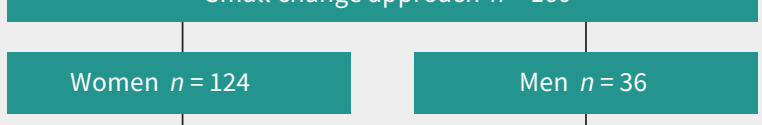

Did not complete

24-mo intervention phase $n=20$

- Dropout $n=2$

- Family issue $n=1$

- Health issue $n=1$

- No contact $n=10$

- Pregnant $n=1$

- Relocated $n=1$

- Time $n=4$

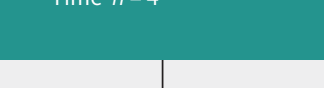

Completed trial $n=104$

Completed trial $n=27$

Did not return for

36-mo follow-up $n=34$

- Dropout $n=8$

- Family issue $n=1$

- Health issue $n=1$

- No contact $n=18$

- Pregnant $n=1$

- Relocated $n=1$

- Time $n=4$
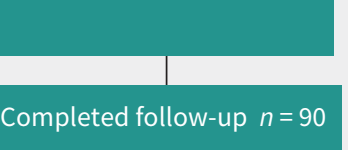

Did not complete

24-mo intervention

phase $n=9$

- Dropout $n=1$

- Family issue $n=2$

- Health issue $n=1$

- No contact $n=3$

- Time $n=2$

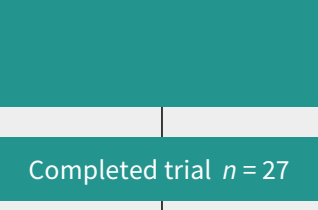

Did not return for

36-mo follow-up $n=11$

- Dropout $n=1$

- Family issue $n=2$

- Health issue $n=1$

- No contact $n=5$

- Time $n=2$

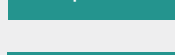

Included in primary analysis $n=160$

Figure 1: Participant flow diagram. 


\section{Statistical analysis}

The primary analysis included all available data from all participants according to the arm to which they were randomized, regardless of treatment adherence.

We used control-based pattern multiple imputation to account for missing data. ${ }^{13}$ We first used within-arm Markov Chain Monte Carlo imputation to impute the nonmonotonic missing data (i.e., missing assessments with subsequent nonmissing assessments), but then imputed the remaining monotonic missing data using regression imputation based on the control arm. ${ }^{14,15}$ The imputation models included age and all available outcome assessments, and were estimated separately by sex. We modelled 100 imputed data sets separately with estimates combined using Rubin's rules to account for within- and between-imputation variance. ${ }^{16}$

We modelled each imputed data set by a covariance pattern model for longitudinal data. ${ }^{17}$ The model allowed for an unstructured mean pattern and unstructured within-subject covariance. The dependent variable was the change in weight from baseline to each follow-up assessment. Independent variables included fixed effects for treatment group, time sex (the stratification factor) and baseline weight, as well as interaction terms to allow the effects of treatment group, sex and baseline weight to vary over time. Contrasts were constructed to estimate the adjusted change and between-group difference in change at each time point. The model was estimated by restricted maximum likelihood using Kenward-Roger degrees of freedom, as implemented in the MIXED procedure of SAS/STAT version 14.1. ${ }^{18}$ Because of convergence problems when accounting for within-couple dependence, we averaged the values of participant couples after imputation, but before applying the linear covariance pattern model. We analyzed waist circumference and $\mathrm{VO}_{2}$ peak using the same approach. We performed prespecified and post hoc subgroup analyses by sex and obesity status, respectively. Details of outlier detection, model diagnostics and sensitivity analyses are provided in Appendix 3, available at www.cmaj.ca/lookup/ doi/10.1503/cmaj.211041/tab-related-content.

\section{Ethics approval}

The study was approved by the Queen's University Health Sciences Research Ethics Board.

\section{Results}

A total of 838 people responded to media advertisements seeking adults with overweight or obesity to participate in a diet and exercise study. Of these, 320 people met the inclusion criteria and agreed to participate in the study, including 25 couples (50 participants) (Figure 1). The mean age and BMI were 52.6 (standard deviation [SD] 10.3) years and 32.6 (SD 4.2), respectively, and $247(77.2 \%)$ participants were women (Table 1 ). Follow-up at 2 and 3 years was $83.8 \%(85.6 \% \mathrm{MA}, 81.9 \% \mathrm{SCA})$ and $74.6 \%$ (77.5\% MA, $71.9 \% \mathrm{SCA})$, respectively .

Adherence to the SCA intervention, defined as the percentage of sessions attended with the interventionist, was $80 \%$. Attendance in group sessions averaged $81 \%$ and attendance in 1-on-1 sessions averaged 77\%; 92 (57.5\%) participants attended at least $90 \%$ of the expected sessions.

\section{Primary outcome}

Reduction in body weight was significantly greater in the SCA group than in the MA group at 3, 6, 12 and 15 months, but was not significantly different at 24 months (mean change -0.9 [standard

\section{Table 1: Participant characteristics}

\begin{tabular}{|c|c|c|c|c|c|c|c|}
\hline \multirow[b]{2}{*}{ Characteristic } & \multicolumn{3}{|c|}{ All participants } & \multicolumn{2}{|c|}{ Men } & \multicolumn{2}{|c|}{ Women } \\
\hline & $\begin{array}{c}\text { Total } \\
n=320\end{array}$ & $\begin{array}{c}\text { MA } \\
n=160\end{array}$ & $\begin{array}{c}\text { SCA } \\
n=160\end{array}$ & $\begin{array}{c}\text { MA } \\
n=37\end{array}$ & $\begin{array}{c}\text { SCA } \\
n=36\end{array}$ & $\begin{array}{c}\text { MA } \\
n=123\end{array}$ & $\begin{array}{c}\text { SCA } \\
n=124\end{array}$ \\
\hline Age, yr, mean \pm SD & $52.6 \pm 10.3$ & $53.0 \pm 10.4$ & $52.2 \pm 10.2$ & $54.5 \pm 10.9$ & $54.9 \pm 10.9$ & $52.5 \pm 10.3$ & $51.4 \pm 9.9$ \\
\hline \multicolumn{8}{|c|}{$\begin{array}{l}\text { Anthropometric measurements, } \\
\text { mean } \pm \text { SD }\end{array}$} \\
\hline Weight, kg & $90.3 \pm 14.5$ & $90.7 \pm 14.0$ & $90.0 \pm 14.9$ & $103.3 \pm 11.8$ & $104.3 \pm 12.7$ & $86.9 \pm 12.4$ & $86.0 \pm 12.9$ \\
\hline Waist circumference, $\mathrm{cm}$ & $107.4 \pm 11.7$ & $108.0 \pm 11.8$ & $106.7 \pm 11.7$ & $117.5 \pm 9.7$ & $114.7 \pm 10.7$ & $105.2 \pm 10.9$ & $104.4 \pm 10.9$ \\
\hline BMI & $32.6 \pm 4.2$ & $32.6 \pm 4.2$ & $32.6 \pm 4.3$ & $33.4 \pm 3.5$ & $32.7 \pm 3.5$ & $32.4 \pm 4.3$ & $32.5 \pm 4.4$ \\
\hline \multicolumn{8}{|l|}{$\begin{array}{l}\text { Blood pressure, } \mathrm{mm} \mathrm{Hg} \\
\text { mean } \pm \mathrm{SD}\end{array}$} \\
\hline Systolic & $122.3 \pm 14.5$ & $121.7 \pm 13.9$ & $122.8 \pm 15.2$ & $125.8 \pm 11.4$ & $127.7 \pm 14.2$ & $120.5 \pm 14.4$ & $121.5 \pm 15.2$ \\
\hline Diastolic & $77.8 \pm 8.3$ & $77.1 \pm 8.0$ & $78.4 \pm 8.6$ & $81.1 \pm 8.5$ & $82.1 \pm 8.1$ & $75.9 \pm 7.5$ & $77.4 \pm 8.5$ \\
\hline \multicolumn{8}{|l|}{$\begin{array}{l}\text { Cardiorespiratory fitness, } \\
\text { mean } \pm \text { SD }\end{array}$} \\
\hline $\mathrm{VO}_{2}$ peak, $\mathrm{L} / \mathrm{min}$ & $2.4 \pm 0.6$ & $2.4 \pm 0.6$ & $2.5 \pm 0.6$ & $3.0 \pm 0.7$ & $3.3 \pm 0.5$ & $2.2 \pm 0.4$ & $2.3 \pm 0.4$ \\
\hline $\mathrm{VO}_{2}$ peak, $\mathrm{mL} / \mathrm{kg} / \mathrm{min}$ & $27.1 \pm 5.5$ & $26.5 \pm 5.4$ & $27.7 \pm 5.6$ & $28.8 \pm 6.7$ & $31.4 \pm 5.2$ & $25.8 \pm 4.8$ & $26.6 \pm 5.2$ \\
\hline
\end{tabular}

Note: $\mathrm{BMI}=$ body mass index, $\mathrm{MA}=$ monitoring alone, $\mathrm{SCA}=$ small change approach, $\mathrm{SD}=$ standard deviation, $\mathrm{VO}_{2}$ peak $=$ highest oxygen uptake value attained on graded exercise test-to-exhaustion. 
error (SE) 0.6] kg v. -0.4 [SE 0.6] kg; mean between-arm difference in change $-0.6,95 \%$ confidence interval $[\mathrm{Cl}]-1.9$ to 0.8 ) or at 36 months ( -1.2 [SE 0.8] kg v. -0.7 [SE 0.8] kg, mean difference $-0.5,95 \% \mathrm{Cl}-2.2$ to 1.2 ) (Table 2 and Figure 2). For women, the reduction in body weight was significantly greater in the SCA group than the MA group at 3, 6, 12, 15 and 18 months, but not at 24 or 36 months (Figure 2). For men, at no assessment time was the reduction in body weight significantly different between groups $(p>0.1)$.

\section{Secondary outcomes}

The mean reduction in waist circumference was greater in the SCA group than the MA group at 3, 6, 9 and 12 months, but was not statistically different at 24 or 36 months (Table 2 ).

\section{Other outcomes}

The improvement in cardiorespiratory fitness was not statistically greater in the SCA group than in the MA group at 24 or 36 months ( $p>0.1$, Table 3$)$. The mean number of steps reported for 154 SCA participants at baseline was 7538 (SE 224) steps. The mean increase from baseline in steps reported at 6 months ( $n=122,2154$ [SE 260] steps), 12 months ( $n=102$, 1711 [SE 237] steps), 18 months ( $n=90,1588$ [SE 267] steps) and 24 months ( $n=80,1619$ [SE 297] steps) were all statistically significant $(p<0.001)$.

\section{Adverse events}

Cardiovascular events and hospitalizations were not materially different in the SCA and MA groups (Appendix 4, available at www. cmaj.ca/lookup/doi/10.1503/cmaj.211041/tab-related-content). Rates of musculoskeletal injuries were also similar between groups.

\section{Sensitivity analysis}

One participant in the MA group lost $42 \mathrm{~kg}$ and had a reduction in waist circumference of $38 \mathrm{~cm}$. Removal of this extreme outlier from analysis did not meaningfully alter the results (Appendix 3, Figures 8 and 9). The use of control-based pattern multiple imputation altered results only trivially compared with the linear covariance pattern model without imputation.

\section{Post hoc subgroup analysis comparing participants with overweight and obesity}

Among participants with overweight (BMI 25-29.9), the SCA group gained $2.4 \mathrm{~kg}(95 \% \mathrm{Cl} 0.3$ to $4.5 \mathrm{~kg})$ and $2.2 \mathrm{~kg}(95 \% \mathrm{Cl} 0.1$ to $4.3 \mathrm{~kg}$ ) less weight than the MA group at 24 and 36 months, respectively (Appendix 5, available at www.cmaj.ca/lookup/ doi/10.1503/cmaj.211041/tab-related-content). Among participants with obesity (BMI $\geq 30)$, the SCA group lost significantly more weight than those in the MA group during the first year, but by 24 and 36 months, weight changes by group were not significantly different (Appendix 5).

\section{Interpretation}

We found that the SCA was not more effective than MA in preventing weight gain at 2 or 3 years in adults with overweight or obesity. We had reasoned that the prevention of weight gain by making small changes in dietary intake or physical activity behaviours would be sustainable long term and would have clinical relevance, as even modest weight gain $(0.5-1.0 \mathrm{~kg} / \mathrm{yr})$ in adults with overweight and obesity is negatively associated with important health outcomes.

Table 2: Body weight and waist circumference during intervention and follow-up periods*

\begin{tabular}{|c|c|c|c|c|c|c|c|c|c|}
\hline \multirow{2}{*}{$\begin{array}{l}\text { Within-group } \\
\text { change }\end{array}$} & \multicolumn{9}{|c|}{ Months } \\
\hline & 3 & 6 & 9 & 12 & 15 & 18 & 24 & 30 & 36 \\
\hline \multicolumn{10}{|l|}{ No. of participants } \\
\hline MA & 144 & 146 & 147 & 141 & 138 & 131 & 137 & 122 & 124 \\
\hline SCA & 144 & 144 & 134 & 134 & 133 & 128 & 131 & 110 & 115 \\
\hline \multicolumn{10}{|l|}{ Change in weight, kg } \\
\hline $\mathrm{MA}$, mean $\pm \mathrm{SE}$ & $-0.3 \pm 0.3$ & $-0.7 \pm 0.4$ & $-0.1 \pm 0.4$ & $-0.6 \pm 0.5$ & $-0.3 \pm 0.6$ & $-0.5 \pm 0.7$ & $-0.4 \pm 0.6$ & $-0.1 \pm 0.7$ & $-0.7 \pm 0.8$ \\
\hline $\mathrm{SCA}$, mean $\pm \mathrm{SE}$ & $-1.3 \pm 0.3$ & $-2.5 \pm 0.4$ & $-2.1 \pm 0.4$ & $-2.5 \pm 0.5$ & $-1.6 \pm 0.7$ & $-1.4 \pm 0.7$ & $-0.9 \pm 0.6$ & $-0.8 \pm 0.7$ & $-1.2 \pm 0.8$ \\
\hline Difference $(95 \% \mathrm{Cl})$ & $\begin{array}{c}-1.0 \\
(-1.6 \text { to }-0.4)\end{array}$ & $\begin{array}{c}-1.9 \\
(-2.7 \text { to }-1.0)\end{array}$ & $\begin{array}{c}-2.0 \\
(-2.9 \text { to }-1.0)\end{array}$ & $\begin{array}{c}-1.8 \\
(-3.0 \text { to }-0.7)\end{array}$ & $\begin{array}{c}-1.4 \\
(-2.7 \text { to }-0.0)\end{array}$ & $\begin{array}{c}-0.9 \\
(-2.3 \text { to } 0.5)\end{array}$ & $\begin{array}{c}-0.6 \\
(-1.9 \text { to } 0.8)\end{array}$ & $\begin{array}{c}-0.7 \\
(-2.2 \text { to } 0.8)\end{array}$ & $\begin{array}{c}-0.5 \\
(-2.2 \text { to } 1.2)\end{array}$ \\
\hline \multicolumn{10}{|l|}{$\begin{array}{l}\text { Change in waist } \\
\text { circumference, } \mathrm{cm}\end{array}$} \\
\hline $\mathrm{MA}$, mean $\pm \mathrm{SE}$ & $-0.3 \pm 0.4$ & $-1.2 \pm 0.4$ & $-1.0 \pm 0.5$ & $-0.9 \pm 0.5$ & $-0.9 \pm 0.6$ & $-0.8 \pm 0.6$ & $-0.3 \pm 0.6$ & $0.0 \pm 0.6$ & $-0.7 \pm 0.8$ \\
\hline $\mathrm{SCA}$, mean $\pm \mathrm{SE}$ & $-1.3 \pm 0.3$ & $-2.4 \pm 0.4$ & $-2.2 \pm 0.5$ & $-2.4 \pm 0.5$ & $-1.5 \pm 0.6$ & $-1.0 \pm 0.6$ & $-0.6 \pm 0.6$ & $0.0 \pm 0.7$ & $-1.3 \pm 0.8$ \\
\hline Difference $(95 \% \mathrm{Cl})$ & $\begin{array}{c}-1.0 \\
(-1.7 \text { to }-0.2)\end{array}$ & $\begin{array}{c}-1.1 \\
(-2.0 \text { to }-0.2)\end{array}$ & $\begin{array}{c}-1.2 \\
(-2.2 \text { to }-0.1)\end{array}$ & $\begin{array}{c}-1.5 \\
(-2.6 \text { to }-0.4)\end{array}$ & $\begin{array}{c}-0.6 \\
(-1.8 \text { to } 0.7)\end{array}$ & $\begin{array}{c}-0.2 \\
(-1.5 \text { to } 1.1)\end{array}$ & $\begin{array}{c}-0.3 \\
(-1.5 \text { to } 0.9)\end{array}$ & $\begin{array}{c}0.0 \\
(-1.4 \text { to } 1.4)\end{array}$ & $\begin{array}{c}-0.6 \\
(-2.3 \text { to } 1.1)\end{array}$ \\
\hline
\end{tabular}

Note: $\mathrm{Cl}$ = confidence interval, $\mathrm{MA}=$ monitoring alone, $\mathrm{SCA}=$ small change approach, $\mathrm{SE}=$ standard error.

*Values are expected mean changes (with standard errors or $95 \%$ confidence intervals, as applicable) from mixed-effects models, adjusted for baseline measurements and sex with control-based multiple imputation of missing values. 
A

All participants

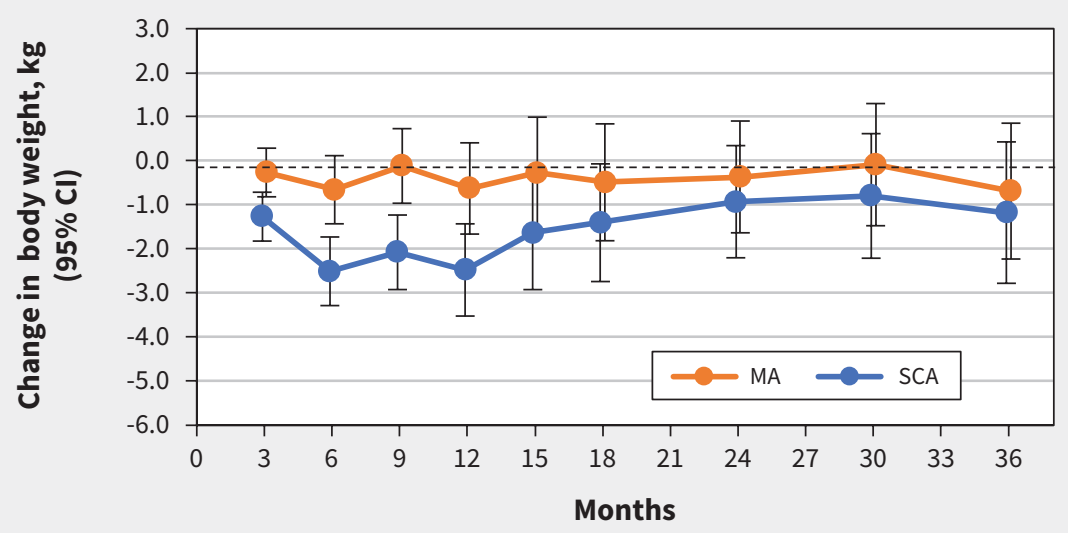

B

Women

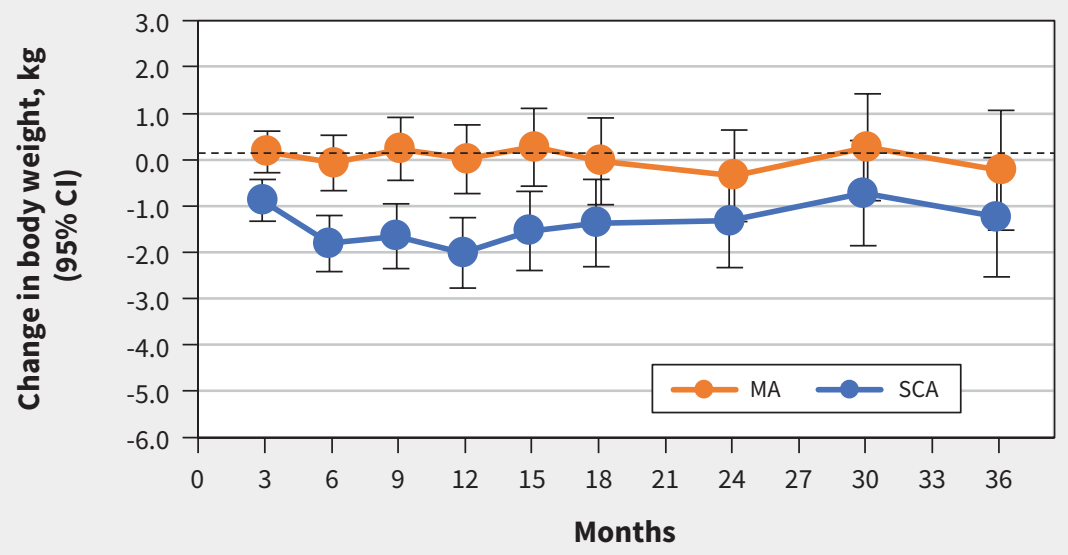

C

Men

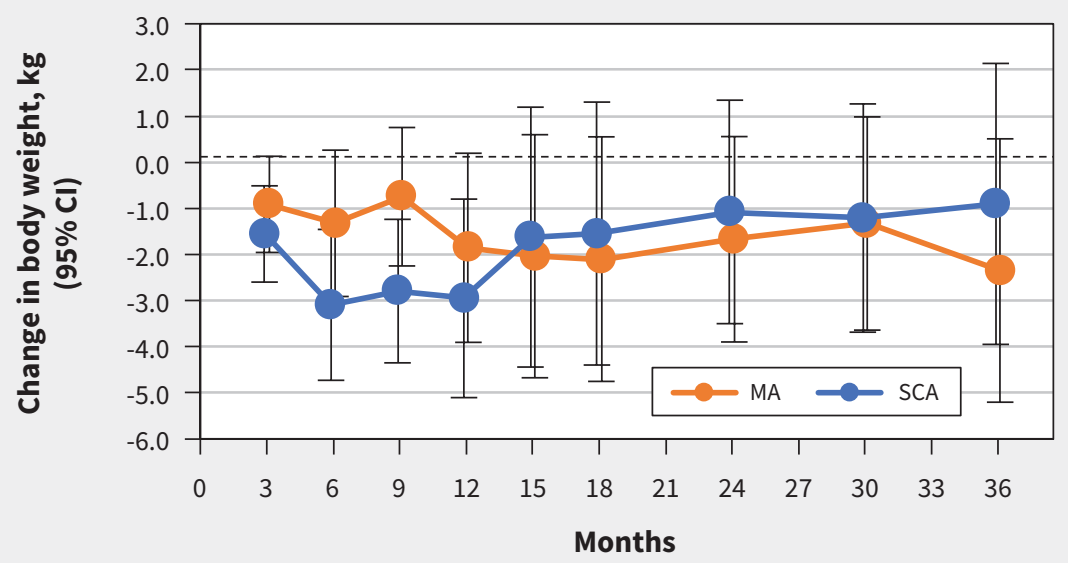

Figure 2: Weight changes over time for (A) all participants, (B) women and (C) men randomized to either a small change approach (SCA) or to monitoring alone (MA). Weight was measured at 3, 6, 9, 12, 15, 18, 24, 30 and 36 months. Error bars indicate 95\% confidence intervals (CI). 


\section{Months}

Within-group change

6

No. of participants
128

118
12

117

114
24

111

98
36

100

90

Change in $\mathrm{VO}_{2}$ peak, $\mathrm{mL} / \mathrm{kg}$ /

$\min$
$\mathrm{MA}$, mean $\pm \mathrm{SE}$
$0.9 \pm 0.4$
$1.4 \pm 0.4$
$1.3 \pm 0.5$
$0.2 \pm 0.6$
$\mathrm{SCA}$, mean $\pm \mathrm{SE}$
$2.3 \pm 0.4$
$2.1 \pm 0.4$
$2.1 \pm 0.5$
$0.5 \pm 0.6$
Difference $(95 \% \mathrm{Cl})$
1.4 (0.5 to 2.3 )
$0.7(-0.3$ to 1.6$)$
$0.8(-0.3$ to 1.8$)$
$0.2(-0.9$ to 1.4$)$

Note: $\mathrm{Cl}=$ confidence interval, $\mathrm{MA}=$ monitoring alone, $\mathrm{SCA}=$ small change approach, $\mathrm{SE}=$ standard error, $\mathrm{VO}_{2}$ peak $=$ highest oxygen uptake value attained on graded exercise test-to-exhaustion.

*Values are adjusted mean changes (with standard errors or $95 \%$ confidence intervals, as applicable) from mixed-effects models, adjusted for baseline measurements and sex with control-based multiple imputation of missing values.

†Participation in the test of cardiorespiratory fitness was optional.

On average, we observed prevention of weight gain in both arms of the trial. People in the MA group actually lost, on average, $0.7 \mathrm{~kg}$ at 3 years, which was unexpected as we had hypothesized that MA would be associated with a weight gain of 1 to $2 \mathrm{~kg}$ over the 3 years, an observation that is consistently reported. ${ }^{19} \mathrm{It}$ is possible that the behaviour of the MA group differed from expected because enrolling in a weight management trial may be an indicator of commitment to behaviour change, which is associated with motivation and intention for change..$^{20,21}$ It is also possible that the frequent monitoring of body weight by health professionals during the trial influenced behaviour. Responding to attention received from trial staff during assessment throughout the trial is akin to a Hawthorne effect. Moreover, monitoring of behaviour by others is an established behaviour change technique.

Our principal finding counters that of a previous report, the Study of Novel Approaches to Weight Gain Prevention (SNAP) trial, wherein the SCA prevented weight gain in a large sample of young adults with overweight over 3 years. ${ }^{11}$ Apart from marked differences between the trials with respect to study participants' age and phenotype (overweight v. obesity), the discrepant findings may be explained by 2 factors. The primary finding reported in the SNAP trial was that, averaged over measurements taken at $4,12,24,36$ and 48 months, the SCA group lost body weight $(0.6 \mathrm{~kg})$ while the control arm gained body weight $(0.3 \mathrm{~kg}$, $p<0.001) .{ }^{11}$ Our main effect, pooling all measurements taken over 36 months, showed a similar benefit for the SCA group (Appendix 3, Table 3a, $p=0.01$ ). However, the significant benefit we observed during the first 15 months was not sustained by 24 months, which was our prespecified primary outcome.

Our post hoc observation that, in the SCA group, weight gain was prevented in adults with overweight, but not in adults with obesity, is consistent with the SNAP trial's finding that the SCA prevented weight gain in adults with overweight. ${ }^{11}$ These observations are hypothesis generating and suggest that the prevention of further weight gain using the SCA may be more effective in adults with overweight than those with obesity.

\section{Limitations}

Our sample comprised predominantly white people and included a disproportionate number of women, which limits the generalizability of our findings. Blinding in lifestyle intervention trials is not possible, which may bias the behaviour of trial participants who are aware of trial objectives and group assignment. However, assessment personnel were blinded to group assignment after randomization and trial participants were asked not to disclose their group assignment to assessment personnel. Our trial was not designed to test the relative contributions of dietary changes, increased physical activity or both to the prevention of weight gain.

\section{Conclusion}

The management of adults with overweight and obesity remains a public health challenge. Our principal finding does not support earlier evidence showing the promise of the small change approach as a pragmatic and more effective strategy for the prevention of weight gain compared with monitoring alone.

\section{References}

1. Wharton S, Lau DCW, Vallis M, et al. Obesity in adults: a clinical practice guideline. CMAJ 2020;192:E875-91.

2. Overweight and obese adults, 2018. Ottawa: Statistics Canada; 2019. Available: https://www150.statcan.gc.ca/n1/pub/82-625-x/2019001/article/00005-eng.htm (accessed 2021 May 16).

3. Ross R, Lam M, Blair SN, et al. Trial of prevention and reduction of obesity through active living in clinical settings: a randomized controlled trial. Arch Intern Med 2012;172:414-24.

4. Wadden TA, Butryn ML, Hong PS, et al. Behavioral treatment of obesity in patients encountered in primary care settings: a systematic review. JAMA 2014; 312:1779-91.

5. Renehan AG, Flood A, Adams KF, et al. Body mass index at different adult ages, weight change, and colorectal cancer risk in the National Institutes of HealthAARP Cohort. Am J Epidemiol 2012;176:1130-40.

6. Adams KF, Leitzmann MF, Ballard-Barbash R, et al. Body mass and weight change in adults in relation to mortality risk. Am J Epidemiol 2014;179:135-44.

7. Sahle BW, Slewa-Younan S, Melaku YA, et al. A bi-directional association between weight change and health-related quality of life: evidence from the 11-year follow-up of 9916 community-dwelling adults. Qual Life Res 2020;29:1697-706. 
8. Hill JO, Wyatt HR, Peters JC. Energy balance and obesity. Circulation 2012; 126:126-32.

9. Zhai $\mathrm{F}$, Wang $\mathrm{H}$, Wang $\mathrm{Z}$, et al. Closing the energy gap to prevent weight gain in China. Obes Rev 2008;9(Suppl 1):107-12.

10. Rodearmel SJ, Wyatt HR, Stroebele N, et al. Small changes in dietary sugar and physical activity as an approach to preventing excessive weight gain: the America on the Move family study. Pediatrics 2007;120:e869-79.

11. Wing RR, Tate DF, Espeland MA, et al. Innovative self-regulation strategies to reduce weight gain in young adults: the Study of Novel Approaches to Weight Gain Prevention (SNAP) randomized clinical trial. JAMA Intern Med 2016; 176:755-62.

12. Ross R, Hill JO, Latimer A, et al. Evaluating a small change approach to preventing long term weight gain in overweight and obese adults - study rationale, design, and methods. Contemp Clin Trials 2016;47:275-81.

13. Ratitch B, O'Kelly M. Implementation of pattern-mixture models using standard SAS/STAT procedures. PharmaSUG 2011;SPO4:1-10.

14. Schafer JL. Analysis of incomplete multivariate data. New York: Chapman \& Hall; 1997. Available: https://www.taylorfrancis.com/books/9780367803025 (accessed 2020 July 22).
15. Rubin D. Multiple imputation for nonresponse in surveys. New York: John Wiley \& Sons; 1987.

16. Little R, Rubin D. Statistical analysis with missing data. 3rd ed. Hoboken (NJ): John Wiley \& Sons; 2019.

17. Verbeke G, Molenberghs G, editors. A model for longitudinal data. In: Linear mixed models for longitudinal data. New York: Springer; 2000:19-29. Available: https://doi.org/10.1007/978-0-387-22775-7_3(accessed 2020 July 13).

18. Little RC, Milliken GA, Stroup WW, et al. SAS for mixed models, second edition. Cary (NC): SAS Institute; 2006:841.

19. Dutton GR, Kim Y, Jacobs DR, et al. 25-year weight gain in a racially balanced sample of U.S. adults: the CARDIA study. Obesity (Silver Spring) 2016;24:1962-8.

20. Michie S, Richardson M, Johnston M, et al. The behavior change technique taxonomy (v1) of 93 hierarchically clustered techniques: building an international consensus for the reporting of behavior change interventions. Ann Behav Med 2013;46:81-95.

21. Connell LE, Carey RN, de Bruin M, et al. Links between behavior change tech niques and mechanisms of action: an expert consensus study. Ann Behav Med 2019;53:708-20.
Competing interests: Robert Ross receives grant funding from the Canadian Institutes of Health Research and is on the scientific advisory board of the Canadian Sugar Institute. James Hill reports consulting fees from General Mills, McCormick Science Institute and Gelesis, and shares in Gelesis and Shakabuku. He receives research funding from the National Cattlemen's Beef Association and book royalties for State of Slim. No other competing interests were declared.

This article has been peer reviewed.

Affiliations: School of Kinesiology and Health Studies (Ross, LatimerCheung) and Department of Medicine, Division of Endocrinology and Metabolism (Ross), Queen's University; Kingston Health Sciences Centre (Day), Kingston, Ont.; AdventHealth Orlando, Translational Research Institute (Brennan), Orlando, Fla.; University of Alabama at Birmingham, Department of Nutritional Sciences (Hill), Birmingham, Ala.

Contributors: All authors contributed to the conception and design of the trial, the acquisition, analysis and interpretation of data, drafting of the manuscript and revising it for important intellectual content. All gave approval of the final version to be published and agreed to be accountable for all aspects of the work.
Content licence: This is an Open Access article distributed in accordance with the terms of the Creative Commons Attribution (CC BY-NC-ND 4.0) licence, which permits use, distribution and reproduction in any medium, provided that the original publication is properly cited, the use is noncommercial (i.e., research or educational use), and no modifications or adaptations are made. See: https://creativecommons.org/licenses/ by-nc-nd/4.0/

Funding: This study was funded by the Canadian Institutes of Health Research (\#130434). The funder had no role in the design or conduct of the trial; data collection or interpretation; preparation or approval of the manuscript; or the decision to submit the manuscript for publication.

Data sharing: Deidentified participant data collected during the trial will be available to external groups upon scientific review. Proposals should be sent to the corresponding author.

Disclaimer: Andrew Day is a biostatistical consultant for CMAJ and was not involved in the editorial decision-making process for this article.

Accepted: Dec. 16, 2021

Correspondence to: Robert Ross, rossr@queensu.ca 